\title{
Regional differences among female patients with heart failure from the Cardiac Insufficiency BIsoprolol Study in ELDerly (CIBIS-ELD)
}

Svetlana Apostolovic ${ }^{1,2}$, Dragana Stanojevic ${ }^{1}$, Mitja Lainscak ${ }^{3,4}$, Goetz Gelbrich ${ }^{5}$, Ruzica Jankovic-Tomasevic ${ }^{1}$, Milan Pavlovic ${ }^{1,2}$, Danijela Djordjevic-Radojkovic ${ }^{1}$, Sonja Salinger-Martinovic ${ }^{1,2}$, Biljana Putnikovic ${ }^{6}$, Slavica Radovanovic ${ }^{7}$, Finn Waagstein ${ }^{8}$, Miloje Tomasevic ${ }^{9}$, Elvis Tahirovic ${ }^{10}$, Simone Inkrot ${ }^{10}$, Lindy Musial-Bright ${ }^{10}$, Hans-Dirk Düngen ${ }^{10}$

${ }^{1}$ Clinic for Cardiovascular Diseases, Clinical Center Nis, Serbia; ${ }^{2}$ Medical Faculty, University Nis, Serbia; ${ }^{3}$ Department of Cardiology, University Clinic of Respiratory and Allergic Diseases, Golnik, Slovenia; ${ }^{4}$ Department of Cardiology, Charité-Universitätsmedizin, Campus Virchow-Klinkum, Applied Cachexia Research, Berlin, Germany; ${ }^{5}$ Institute of Clinical Epidemiology and Biometry, University of Würzburg, Würzburg, Germany; ${ }^{6}$ Department of Cardiology, Clinical Hospital Center Zemun, Faculty of Medicine, University of Belgrade, Belgrade, Serbia; ${ }^{7}$ Department of Cardiology, Clinical Hospital Center Bezanijska

Kosa, Belgrade, Serbia; ${ }^{8}$ Department of Cardiology, Clinical Center Serbia, Belgrade, Serbia

${ }^{9}$ Sahlgrenska University, Göteborg, Sweden; ${ }^{10}$ Department of Internal Medicine-Cardiology,

Charité-Universitätsmedizin, Campus Virchow-Klinikum, Berlin, Germany

\begin{abstract}
Background: The aim of our study was to examine regional differences in the demographics, etiology, risk factors, comorbidities and treatment of female patients with heart failure (HF) in the Cardiac Insufficiency BIsoprolol Study in ELDerly (CIBIS-ELD) clinical trial.

Methods and results: One hundred and fifty-nine female patients from Germany and 169 from Southeastern (SE) Europe (Serbia, Slovenia and Montenegro) were included in this subanalysis of the CIBIS-ELD trial. Women comprised 54\% of the study population in Germany and 29\% in SE Europe. German patients were significantly older. The leading cause of HF was arterial hypertension in German patients, $71.7 \%$ of whom had a preserved ejection fraction. The leading etiology in SE Europe was the coronary artery disease; $67.6 \%$ of these patients had a reduced left ventricular ejection fraction (34.64 $\pm 7.75 \%)$. No significant differences were found in the prevalence of traditional cardiovascular risk factors between the two regions (hypertension, diabetes, hypercholesterolemia, smoking and family history of myocardial infarction). Depression, chronic obstructive pulmonary disease and malignancies were the comorbidities that were noted more frequently in the German patients, while the patients from SE Europe had a lower glomerular filtration rate. Compared with the German HF patients, the females in $S E$ Europe received significantly more angiotensin converting enzyme inhibitors, loop diuretics and less frequently angiotensin receptor blockers and mineralocorticoid receptor antagonists.

Conclusions: Significant regional differences were noted in the etiology, comorbidities and treatment of female patients with HF despite similar risk factors. Such differences should be considered in the design and implementation of future clinical trials, especially as women remain underrepresented in large trial populations. (Cardiol J 2014; 21, 3: 265-272)
\end{abstract}

Key words: heart failure, diastolic, systolic, female, clinical trial

Address for correspondence: Dr Dragana Stanojevic, Bulevar dr Zorana Djindjica 48, 18000 Nis, Serbia, tel/fax: +381184221674, e-mail: draganastanojevic1@gmail.com

Received: 11.05.2013 Accepted: 03.08.2013 


\section{Introduction}

Cardiovascular diseases are the main cause of mortality in the European Union, accounting for near $40 \%$ of deaths in the total population. Around $1-2 \%$ of the population in European countries suffers from heart failure (HF), with the prevalence rising to $\geq 10 \%$ among the population aged $\geq 70$ years [1].

Underrepresentation of women in cardiovascular trials has been clearly demonstrated in the past. Since 2006, 11 randomized trials of HF have included 46,141 patients, 12,834 of whom were women (27.8\%, range 15-60\%).

In Europe women have a longer life expectancy with marked differences among different countries. This gender gap in life expectancy, favoring women, shows a threefold variation among the countries [2].

The past decade has seen a trend toward the globalization of clinical trials with greater participation of the emerging countries [3]. The balance among the regions represented in the trial is important in order to avoid over-representation and possible interpretation bias. Despite relatively strict inclusion and exclusion criteria in $\mathrm{HF}$ trials, patient populations remained heterogeneous among the regions in terms of baseline characteristics, treatment and outcomes. However, regional differences should not discourage the globalization of clinical trials; it is interesting to note that subgroup analyses based on geographical regions have rarely changed the main results of $\mathrm{HF}$ trials $[4,5]$.

Although women comprise $40 \%$ of the $\mathrm{HF}$ population, they are underrepresented in clinical trials [6]. Cardiovascular diseases are the leading cause of death in Europe among women, proportionally more than among men (54\% vs. $43 \%$ ). However, this is not reflected in current HF registries, which have a predominately male population from Western European countries. Furthermore, current guidelines do not include gender-related management recommendations.

Little is known about gender-related differences in HF patients in terms of clinical characteristics, echocardiographic measures and outcomes. Women more frequently have HF with preserved left ventricular (LV) function. They are also significantly older than male HF patients, probably due to the later onset of $\mathrm{HF}[7,8]$.

The multinational, multicenter, prospective, randomized Cardiac Insufficiency BIsoprolol Study in ELDerly (CIBIS-ELD) study, which compared the short-term titration of bisoprolol and carvedilol in $\mathrm{HF}$ patients, lends itself particularly to the exploration of basic regional differences in an underrepresented population - elderly female patients with chronic HF from Germany and Southeastern (SE) Europe.

The aim of our study was to compare female populations with chronic HF from these two different regions focusing on the differences which could influence the design of future clinical trials and ultimately to the guidelines development.

\section{Methods}

CIBIS ELD is a double-blind superiority trial comparing the titration of bisoprolol vs. carvedilol in elderly patients suffering from $\mathrm{HF}$ with the reduced ejection fraction ( $\mathrm{HFrEF}$ ) or $\mathrm{HF}$ with preserved ejection fraction (HFpEF). Patients were 65 years old or older with the symptomatic chronic HF consistent with New York Heart Association (NYHA) functional class $\geq$ II at the time of inclusion or with $\mathrm{LVEF} \leq 45 \%$. At the beginning of the study, participants had to be beta-blocker naïve or on $\leq 25 \%$ of the guideline-recommended target or equivalent dose. The study participants had to be clinically stable and on stable medication for 2 weeks prior to randomization. Major exclusion criteria were: known contraindications to beta-blocker treatment, such as hypotension with a resting systolic blood pressure $<90 \mathrm{~mm} \mathrm{Hg}$, severe pulmonary disease or severe asthma, heart rate $<55 /$ min prior to the commencement of the therapy, the second or third degree sinoatrial block (without pacemaker), and diagnosed sick sinus syndrome. Tolerability, defined as achieving guideline-recommended beta-blocker doses after 12 weeks, was assessed as the primary endpoint [9].

In this analysis based on the CIBIS-ELD study population we included 159 patients from Germany (54\% of all the included patients from Germany) and 169 patients from SE Europe (29\% of all the included patients from SE Europe). Female patients from Germany and SE Europe had different profiles of cardiovascular characteristics, co-morbidities, and risk factors.

Baseline variables were presented as frequencies and percentages for binary variables or means and standard deviations for quantitative variables. Comparisons of the groups were performed by the $\chi^{2}$ test or analysis of variance, respectively. $\mathrm{P}<0.05$ was considered statistically significant. SPSS version 17 was used as statistical software. 


\section{Results}

\section{General characteristics}

Baseline characteristics are presented in Table 1. Women from Germany were significantly older, with a shorter duration of HF. There was a significant difference in $\mathrm{HF}$ etiology observed between the two regions. HFpEF was the most common type in women from Germany (71.7\%) compared to HFrEF in women from SE Europe (67.6\%). In SE European patients with HFrEF the average LVEF was $34.64 \pm 7.75 \%$, while in the same subgroup of German female patients it was $35.74 \pm 8.72 \%$.

In the majority of patients dyspnea was reported on mild exertion (NYHA class II) (Fig. 1). However, there were significant differences in NYHA class distribution between the observed groups $\left(\chi^{2}=10.89, \mathrm{p}<0.05\right)$. The patients in SE Europe were generally more symptomatic than the German patients. Similarly, female patients from SE Europe had significantly higher $\mathrm{N}$-terminal prohormone of B-type natriuretic peptide (NT-proBNP) levels at the beginning and at the end of the study (Table 1).

\section{Risk factors}

There were no significant differences in smoking habits (Fig. 2). Hyperlipidemia was similarly distributed in both regions (prevalence in Germany $67.9 \%$ vs. SE Europe $63.9 \%, p=0.485$; cholesterol level $5.54 \pm 1.23$ vs. $5.76 \pm 1.56 \mathrm{mmol} / \mathrm{L}$, $\mathrm{p}=0.167)$. There were no significant differences in percentages of reported family history of fatal myocardial infarction (MI) before the age of 60 years (Germany and SE Europe: $20.1 \%$ vs. $15.4 \%$, $\mathrm{p}=0.164)$.

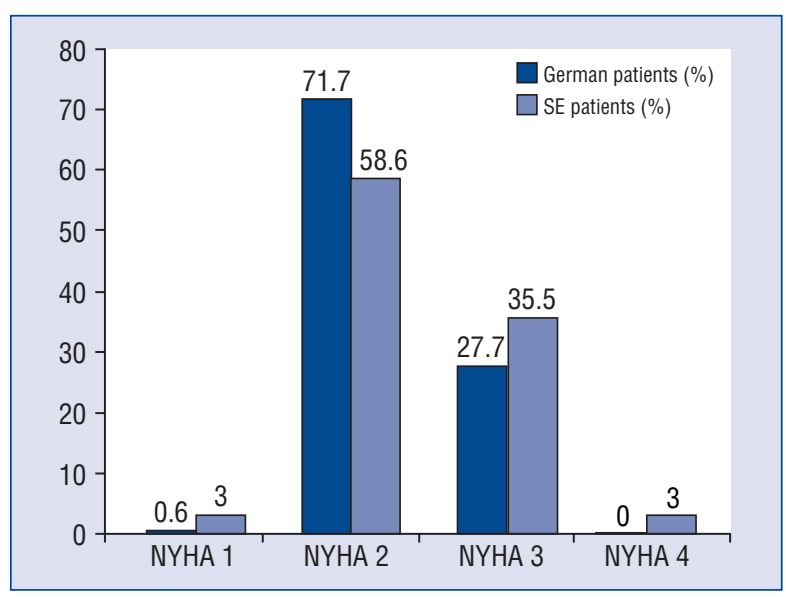

Figure 1. Distribution of functional New York Heart Association classes in patients from Germany and Southeastern Europe.

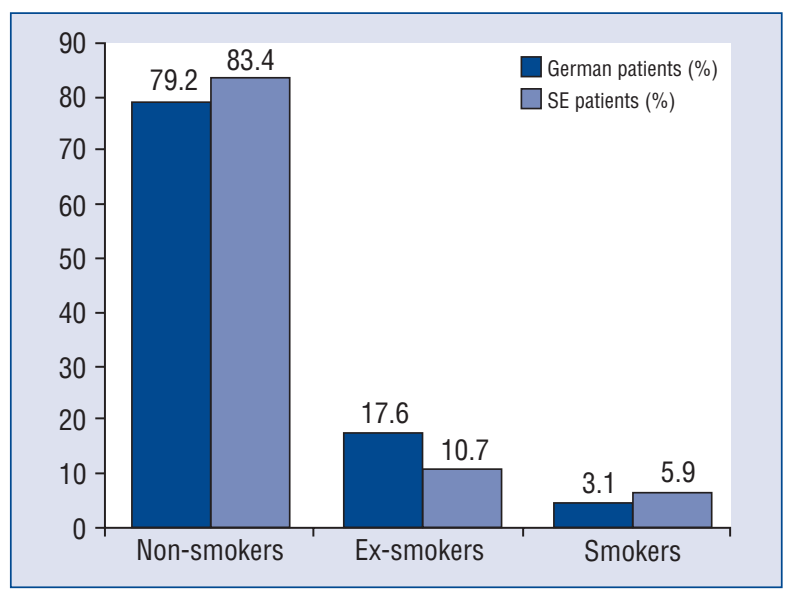

Figure 2. Smoking habits between German and patients from Southeastern Europe.

Table 1. Baseline patients' characteristics.

\begin{tabular}{lccc}
\hline Patients' characteristics & $\begin{array}{c}\text { Female patients } \\
\text { from Germany }\end{array}$ & $\begin{array}{c}\text { Female patients } \\
\text { from SE Europe }\end{array}$ & P \\
\hline Age [years] & $74.13 \pm 6.16$ & $72.20 \pm 4.84$ & $<0.01$ \\
Duration of HF [years] & $1.49 \pm 3.88$ & $5.47 \pm 6.17$ & $<0.001$ \\
Etiology of HF & $\mathrm{AH}: 65.2 \%$ & $\mathrm{CAD}: 46.3 \%$ & $<0.001$ \\
History of angina pectoris and MI & $35.5 \% / 15.1 \%$ & $82.6 \% / 17.4 \%$ & $<0.001 /$ \\
& & $32.4 \%$ & $<0.001$ \\
HFpEF & $71.7 \%$ & $16.6 \%$ & $<0.001$ \\
Atrial fibrillation & $6.9 \%$ & $1.8 \%$ & $<0.01$ \\
Pacemaker rhythm & $3.1 \%$ & $1560.5 \pm 2242.9$ & $<0.001$ \\
Baseline NT-proBNP levels [pg/mL] & $645.5 \pm 1163.1$ & $1145.3 \pm 469.5$ & $<0.01$ \\
Post-treatment NT-proBNP levels & $673.8 \pm 1162.04$ & $36.68 \pm 9.6 \%$ & $<0.001$ \\
at the end of study [pg/mL] & $51.57 \pm 14.8 \%$ & & $<0.001$ \\
Left ventricular ejection fraction & & & $<$ \\
\hline
\end{tabular}

$\mathrm{AH}$ - arterial hypertension; CAD — coronary artery disease; $\mathrm{HF}$ - heart failure; $\mathrm{HFpEF}$ — heart failure with preserved ejection fraction; $\mathrm{MI}$ myocardial infarction; NT-proBNP - N-terminal prohormone of B-type natriuretic peptide; SE - Southeastern 
No difference was observed in the prevalence of arterial hypertension (Germany vs. SE Europe: $86.8 \%$ vs. $88.2 \%, \mathrm{p}=0.741$ ), however there were significant differences in its severity. Women from SE Europe more commonly had mild hypertension (stage 2 according to ESC guidelines) in comparison to those from Germany, where stages 3 and 4 were more frequently observed $\left(\chi^{2}=13.5\right.$, $\mathrm{p}<0.01)[10]$.

Women from Germany were more commonly obese than those from SE Europe (body mass in$\operatorname{dex}[\mathrm{BMI}]: 30.3 \pm 6.5$ vs. $27.7 \pm 4.9, \mathrm{~F}=16.675$, $\mathrm{p}<0.001)$.

Alcohol consumption was different between the observed groups: $\chi^{2}=29.86, p<0.01$. Only $10.7 \%$ of the SE European patients reported alcohol consumption compared to $29.1 \%$ of the German patients. The majority of the German patients consumed only 1 drink per week defined as $0.25 \mathrm{~L}$ of beer or $0.1 \mathrm{~L}$ of wine or $2 \mathrm{cl}$ liquor.

Hyperuricemia was more prevalent among the patients from Germany: $15.1 \%$ vs. $2.4 \%, \chi^{2}=16.99$, $\mathrm{p}<0.001$.

\section{Comorbidities}

No significant differences were observed in the prevalence of diabetes, cerebrovascular morbidity, anemia (hemoglobin levels: $13.25 \pm 1.44$ vs. $12.97 \pm$ $\pm 1.44 \mathrm{mg} / \mathrm{dL}, \mathrm{p}=0.08$ ) and renal diseases (Fig. 3) between the female patients from Germany and those from SE Europe.

However, despite similar rates of previously known renal diseases (diagnosed and treated by nephrologists), we found significant differences in creatinine values (Germany: $83.74 \pm 28.93 \mu \mathrm{mol} / \mathrm{L}$ vs. SE Europe: $95.37 \pm 34.2 \mu \mathrm{mol} / \mathrm{L}, \mathrm{p}<0.001)$ and concurrent glomerular filtration rate (GFR) calculated with Modification of Diet in Renal Disease formula (Germany: $68.22 \pm 26.88 \mathrm{~mL} / \mathrm{min}$ vs. SE Europe: $57.98 \pm 20.63 \mathrm{~mL} / \mathrm{min}, \mathrm{p}<0.001$ ) [11].

Women from Germany more frequently had the chronic obstructive pulmonary disease (COPD) $\left(10.1 \%\right.$ vs. $\left.2.4 \%, \chi^{2}=8.5, p<0.01\right)$, depression $\left(18.9 \%\right.$ vs. $\left.4.1 \%, \chi^{2}=17.75, \mathrm{p}<0.001\right)$ and malignant diseases $(13.8 \%$ vs. $1.2 \%, \mathrm{p}<0.0001)$.

\section{Socio-economic characteristics \\ and the use of medical services}

There was a considerable diversity regarding patients' level of education, but in general, those from Germany had a higher education level. More patients from SE Europe reported not having any education $(14.1 \%$ vs. $4.2 \%, \mathrm{p}<0.001)$. There were significantly more patients with only primary

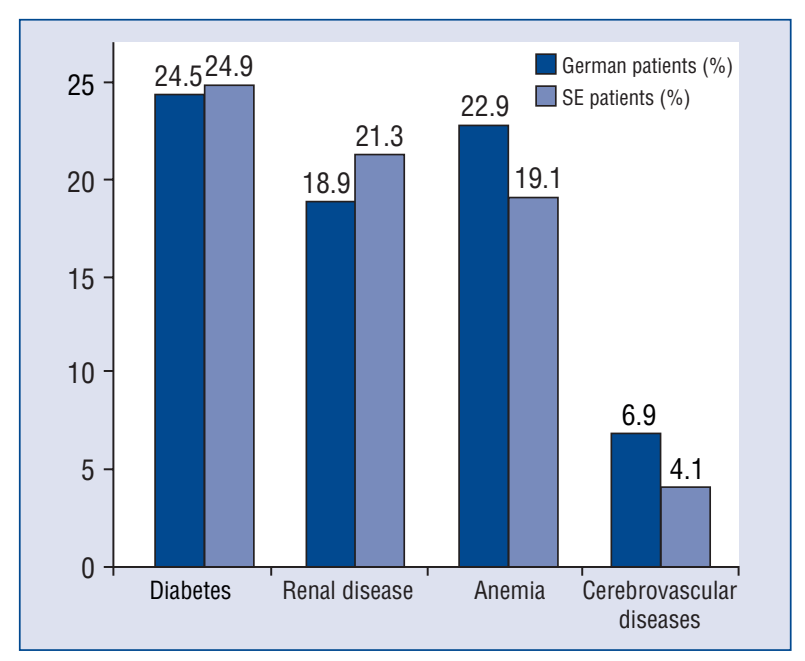

Figure 3. Co-morbidities in female German and patients from Southeastern Europe.

education in Germany (32.5\% vs. 19.5\%, $\mathrm{p}<0.01$ ), while more patients from SE Europe reported having finished the secondary school (28.9\% vs. $15 \%$, $\mathrm{p}<0.01$ ). Twenty-six German patients and only 6 from SE Europe had university degrees $(p<0.001)$.

Women from SE Europe more frequently visited the cardiologist during 1 year (Table 2).

\section{Heart failure therapy and concomitant medication}

Significant differences were noted in the HF therapy in the observed patients (Table 3). Prior to the inclusion in the study more women from SE Europe were taking beta-blockers $(66.3 \%$ vs. $40.3 \%$, p < 0.001). Similar results for beta-blocker therapy were observed for the subgroup of patients with the diastolic dysfunction (SE Europe and Germany: $76.9 \%$ vs. $37.7 \%$ ). There were also differences in the type of the prescribed beta-blocker. Female patients from Germany most frequently used the selective beta ${ }_{1}$ receptor blocker metoprolol $51.6 \%$, while women from SE Europe were prescribed most frequently the nonselective beta/alpha ${ }_{1}$ blocker carvedilol $39.6 \%$ ( $<<0.001)$.

Patients from SE Europe more frequently had angiotensin converting enzyme (ACE) inhibitors, acetylsalicylic acid, organic nitrates, oral anticoagulants, antiarrhythmic agents and loop diuretics and less frequently angiotensin receptor blockers (ARB), mineralocorticoid receptor antagonists (MRAs), antidepressants and allopurinol. No difference was observed regarding the device and surgical therapy for cardiovascular diseases (Table 4). 
Table 2. Number of contacts with health care professionals in patients from Germany and Southeastern (SE) Europe.

\begin{tabular}{lccc}
\hline $\begin{array}{l}\text { Number of contact with health care } \\
\text { professionals during 1 year }\end{array}$ & $\begin{array}{c}\text { Patients from } \\
\text { Germany }\end{array}$ & $\begin{array}{c}\text { Patients from } \\
\text { SE Europe }\end{array}$ & P \\
\hline $\begin{array}{l}\text { Number of visits to cardiologist } \\
\text { during 1 year }\end{array}$ & $2.9 \pm 1.9$ & $0.67 \pm 1.2$ & 0.409 \\
$\begin{array}{l}\text { Number of visits to primary care physician } \\
\text { during 1 year }\end{array}$ & $6.2 \pm 5.9$ & $6.67 \pm 4.2$ & 0.951 \\
$\begin{array}{l}\text { Number of hospitalizations during 1 year } \\
\text { due to worsening heart failure }\end{array}$ & $0.31 \pm 0.73$ & $0.44 \pm 0.63$ & 0.82 \\
$\begin{array}{l}\text { Number of hospitalizations in rehabilitation } \\
\text { facilities during 1 year due to heart failure }\end{array}$ & $0.06 \pm 0.25$ & $0.06 \pm 0.28$ & \\
\hline
\end{tabular}

Table 3. Therapy in patients from Germany and Southeastern (SE) Europe.

\begin{tabular}{|c|c|c|c|c|c|c|}
\hline Drug & $\begin{array}{c}\text { Germany } \\
\text { patients } \\
(n=159)\end{array}$ & $\begin{array}{c}\text { SE Europe } \\
\text { patients } \\
(n=169)\end{array}$ & $\mathbf{P}$ & $\begin{array}{c}\text { Germany } \\
\text { patients with } \\
\text { HFpEF } \\
(\mathbf{n}=114)\end{array}$ & $\begin{array}{l}\text { SE Europe } \\
\text { with HFpEF } \\
(\mathrm{n}=55)\end{array}$ & $\mathbf{P}$ \\
\hline ACEI/ARB & $50.9 \%$ & $85.2 \%$ & NS & $29.8 \%$ & $3.8 \%$ & $<0.05$ \\
\hline Loop diuretics & $27 \%$ & $46.7 \%$ & $<0.001$ & $23.7 \%$ & $19.2 \%$ & NS \\
\hline Thiazide diuretics & $33.3 \%$ & $27.8 \%$ & NS & $38.6 \%$ & $53.8 \%$ & NS \\
\hline $\begin{array}{l}\text { Mineralocorticoid receptor } \\
\text { antagonists }\end{array}$ & $36.1 \%$ & $6.9 \%$ & $<0.001$ & $1.8 \%$ & $15.4 \%$ & $<0.05$ \\
\hline Digitalis & $7.5 \%$ & $10.1 \%$ & NS & $2.6 \%$ & $7.7 \%$ & NS \\
\hline Organic nitrates & $6.9 \%$ & $39.1 \%$ & $<0.001$ & $6.1 \%$ & $23.1 \%$ & $<0.05$ \\
\hline Calcium channel blockers & $18.4 \%$ & $23.7 \%$ & NS & $21.2 \%$ & $46.2 \%$ & $<0.05$ \\
\hline Antiarrhythmics & $0.6 \%$ & $11.2 \%$ & $<0.001$ & $0.9 \%$ & $3.8 \%$ & NS \\
\hline Statins & $28.9 \%$ & $39.1 \%$ & 0.053 & $26.3 \%$ & $30.8 \%$ & NS \\
\hline Other lipid lowering agents & $1.3 \%$ & $1.2 \%$ & NS & $1.8 \%$ & $0 \%$ & NS \\
\hline Acetylsalicylic acid & $41.5 \%$ & $68.6 \%$ & $<0.001$ & $36.8 \%$ & $65.4 \%$ & $<0.001$ \\
\hline Other antiplatelet therapy & $5.7 \%$ & $5.3 \%$ & NS & $1.5 \%$ & $0 \%$ & NS \\
\hline $\begin{array}{l}\text { Oral anticoagulants - } \\
\text { vitamin } \mathrm{K} \text { antagonists }\end{array}$ & $10.1 \%$ & $18.9 \%$ & $<0.05$ & $7 \%$ & $7.7 \%$ & NS \\
\hline Other oral anticoagulants & $1.3 \%$ & $1.8 \%$ & NS & $0.9 \%$ & $0.0 \%$ & NS \\
\hline Antidepressants & $7.5 \%$ & $1.2 \%$ & $<0.01$ & $7 \%$ & $3.8 \%$ & NS \\
\hline Allopurinol & $6.9 \%$ & $0.0 \%$ & $<0.001$ & $78.6 \%$ & $0.0 \%$ & $<0.001$ \\
\hline
\end{tabular}

ACEI — angiotensin converting enzyme inhibitors; ARB — angiotensin receptor blockers; HFpEF — heart failure with preserved ejection fraction

Table 4. Device therapy or cardiovascular surgery in patients from Germany and Southeastern (SE) Europe.

\begin{tabular}{lccc}
\hline Device or surgical therapy & $\begin{array}{c}\text { Germany patients } \\
(\mathbf{n}=\mathbf{1 5 9 )}\end{array}$ & $\begin{array}{c}\text { SE Europe patients } \\
(\mathbf{n}=\mathbf{1 6 9})\end{array}$ & $\mathbf{P}$ \\
\hline Valvular replacement & $3.1 \%$ & $3.6 \%$ & $\mathrm{NS}$ \\
Coronary artery bypass graft & $3.1 \%$ & $8.9 \%$ & 0.058 \\
Percutaneous coronary intervention & $11.3 \%$ & $5.9 \%$ & $\mathrm{NS}$ \\
Pacemaker & $4.4 \%$ & $3 \%$ & $\mathrm{NS}$ \\
Cardiac resynchronization therapy & $1.3 \%$ & $0 \%$ & $\mathrm{NS}$ \\
Implantable cardioverter-defibrillator & $0.6 \%$ & $0 \%$ & $\mathrm{NS}$ \\
\hline
\end{tabular}




\section{Discussion}

Female population was underrepresented in SE Europe considering that in both regions patients were recruited in consecutive order during their regular visits to a cardiologist.

Our results showed marked differences in the etiology and treatment of HF in elderly female population from different parts of Europe.

In Germany, arterial hypertension was the most common cause of $\mathrm{HF}$ in women, while in SE Europe it was the coronary heart disease (CHD). No regional differences in the prevalence of arterial hypertension were found in this study (but it was more severe in female patients from Germany), although the data from the EVEREST study suggest that it is more prevalent in Eastern Europe [12].

Women from SE Europe develop HF earlier than German women, which could be attributed to coronary events which occurred at the younger age [5]. These results are in accordance with the higher rates of MI in Eastern Europe reported in a series of studies, where it was attributed partly to socioeconomic factors - lower education in women and lower income, emotional stress, unhealthy dietary style, and less physical activity as the most prominent but not all the factors [13]. The rates of MI in women correlate closely with the reported rates in men in different parts of Europe, suggesting also that the environmental and lifestyle factors have significant influence on CHD development beside the "traditional risk factors" - genetics and gender [14].

Our female patients had similar cardiovascular risk factors with several key differences. In contrast to the previously published data that smoking-related mortality is higher in Eastern European countries [15], we found no significant regional differences in tobacco use. This could be attributed to the fact that we observed only elderly female population. German patients more frequently consumed alcohol but moderately ( 1 drink per week), which is consistent with previous studies of alcohol consumption in women with higher education and socio-economic status. Furthermore, moderate alcohol intake may have a protective effect against CHD [16, 17].

German patients had a higher average BMI and were more frequently diagnosed with hyperuricemia. Recent data indicate, however, that Eastern European countries have the highest obesity prevalence rates for both genders, which is explained by a transition in the social, economic, and nutritional environments followed by the delayed effect of the
Western lifestyle in the countries of the former "Eastern Bloc" [18-20].

Differences in BMI seen in this study could be due to HF duration, because HF has inflammatory components and leads to a progressive weight loss over time. The females from SE Europe had a longer history of HF and hence they had more complications of the disease itself, including the weight loss.

In SE Europe patients NT-proBNP levels were higher. Because measurements of NT-proBNP levels are useful in both diagnosis and prognosis in patients with chronic HF [21], this finding could suggest either more clinically severe $\mathrm{HF}$ or the undertreatment with poorer subsequent prognoses in SE Europe patients.

HF patients usually have 1 or more comorbidities, which are complications of HF or the combination of HF, its underlying etiology and advanced age [22]. Similarly, our patients had a high prevalence of anemia and diabetes. However, there was no significant differences between the regions. Previous studies reported higher prevalence of chronic kidney diseases in Western Europe [12], although in our study patients from SE Europe had lower GFR, which could be attributed to longer disease duration, more severe forms of HF in those patients and, possibly, the applied therapy. Interestingly, higher NT-proBNP levels could be attributed not only to lower LVEF but also to the lower GFR in SE Europe patients [23].

As previously described, we also found regional differences in the prevalence of COPD [12]. German patients had more frequently COPD, which could be attributed in our study population to more frequent obesity in these patients [24]. Primary pulmonary hypertension was rare, while secondary pulmonary hypertension is a common feature of $\mathrm{HF}$ and it is associated with high morbidity and mortality $[25,26]$.

The patients from SE Europe more frequently had atrial fibrillation, which could be attributed to a higher prevalence of HFrEF and valvular disease [27].

The female patients from Germany more frequently had malignant diseases, which are more prevalent in developed, high income countries; regional variation has been attributed to different lifestyle and environmental factors [28]. In our study, females from SE Europe had less frequent depression and less frequently took antidepressants than those living in Germany, which is not in accordance with previous publications [29].

We found marked differences in the socioeconomic composition of the German and SE European study populations, which could have relevant impact 
on health care use and outcomes. Although most health professionals may see CHD merely as a problem of the individual, socioeconomic factors are key determinants of $\mathrm{CHD}$ and its related risk factors. Both health care and schooling are in the group of socioeconomic factors, which could act next to the traditional risk factors [14]. While the control of traditional risk factors is not incompatible with strategies at the societal level, in order to effectively reduce cardiovascular mortality in both developed and developing societies, a broader socioeconomic approach is needed. German participants were more likely to have a university degree. Also, the pension system in Western Europe provides significantly higher monthly payment than those from SE Europe. More frequent visits to cardiologists in SE European countries could be ascribed to a more direct contact, which does not require always a referral from the patient's primary care physician.

Different drugs were used in the observed groups of patients, which is in accordance with previous trials, in which different therapeutic approaches in $\mathrm{HFpEF}$ and $\mathrm{HFrEF}$ were investigated [30]. Since patients from SE Europe more frequently had $\mathrm{CHD}$, they more frequently used organic nitrates, antiarrhythmics, platelet aggregation inhibitors and anticoagulant therapy. Loop diuretics were more frequently used in patients with $\mathrm{HFrEF}$ from SE Europe, as well as ACE inhibitors (in both HFrEF and HFpEF patients). German patients more frequently used ARBs. Although digitalis is used to manage symptoms of $\mathrm{HF}$ it was not used more frequently in patients with HFrEF. In German patients MRAs were more frequently used, however in the subgroup of SE Europe patients with $\mathrm{HFpEF}$ those drugs were more frequently prescribed. More women from SE Europe were taking beta-blockers prior to inclusion in the study, which could be attributed to a higher rate of coronary artery disease in SE Europe. Similar results were observed for the subgroup of patients with the diastolic dysfunction. There were also differences in the type of prescribed beta-blocker. Female patients from Germany most frequently took the selective beta ${ }_{1}$ receptor blocker which could be attributed to more frequent COPD.

\section{Limitations of the study}

All patients took part in a controlled, randomized trial with strict inclusion and exclusion criteria and different recruitment methods, therefore obtained results are not representative of the German and SE European population.

\section{Conclusions}

We found significant regional differences in female HF patients regarding the etiology, comorbidities and treatment. No significant differences were observed in the prevalence of traditional cardiovascular risk factors (hypertension, diabetes, hypercholesterolemia, smoking and family history of MI). Female population from SE Europe was underrepresented (29\% of all participants) in comparison to those from Germany (54\% of the study population). Taking into the consideration that this was a trial with strict inclusion/exclusion criteria, and our recruitment method was similar we could speculate that females from SE Europe could have less frequent $\mathrm{HF}$, under-diagnosed $\mathrm{HF}$, higher mortality from CHD and less odds to develop HF, but the end-result is decisively the same - female patients from SE Europe were underrepresented in the trial.

The current guidelines on HF from ESC and other cardiology societies do not include specific gender-related issues, except in the case of pregnancy. No regional differences are even considered. All the mentioned differences should be considered in the design and implementation of future clinical trials, especially as women have been underrepresented in large trial populations for the past few decades. Furthermore, not only the women but elderly have often been either excluded or underrepresented in cardiovascular trials, and as such the evidence base is rather unsatisfactorily drawn either from the observational cohorts or from small numbers within larger randomized trials.

There is a need that cardiovascular trials incorporate sufficient number of patients with different gender, age, and ethnicity to provide better insights in disease etiopathology, diagnosis and treatment.

\section{Acknowledgements}

This study was supported by the German Competence Network Heart Failure, funded by the Federal Ministry of Education and Research (BMBF), FKZ 01GI0205.

\section{Conflict of interest: none declared}

\section{References}

1. Laribi S, Aouba A, Nikolaou M et al. GREAT network. Trends in death attributed to heart failure over the past two decades in Europe. Eur J Heart Fail, 2012; 14: 234-239.

2. Jagger C, Gillies C, Moscone F et al. Inequalities in healthy life years in the 25 countries of the European Union in 2005: A cross-national meta-regression analysis. Lancet, 2008; 372: 2124-2131. 
3. George M, Selvarajan S, Suresh-Kumar S, Dkhar SA, Chandrasekaran A. Globalization of Clinical Trials: Where are we Heading? Curr Clin Pharmacol, 2013; 8: 115-123.

4. Heiat A, Gross CP, Krumholz HM. Representation of the elderly, women, and minorities in heart failure clinical trials. Arch Intern Med, 2002; 162: 1682-1688.

5. Panico S, Mattiello A. Epidemiology of cardiovascular diseases in women in Europe. Nutr Metab Cardiovasc Dis, 2010; 6: 379-385.

6. Stramba-Badiale M. Women and research on cardiovascular diseases in Europe: A report from the European Heart Health Strategy (EuroHeart) project. Eur Heart J, 2010; 31: 1677-1685.

7. Vanuzzo D. Gender gap in cardiovascular risk factors. Morbidity and mortality. Presented at the ESC Congress. Paris, 2011. http:// www.escardio.org (accessed 20 September 2011).

8. Allender S, Scharbotough P, Peto V, Rayner M, Leal J, Luengo-Fernandez R, Gray A. European cardiovascular disease statistics: 2008 edition. British Heart Foundation, London 2008.

9. Düngen HD, Apostolović S, Inkrot S et al. Titration to target dose of bisoprolol vs. carvedilol in elderly patients with heart failure: the CIBIS-ELD trial. Eur J Heart Fail, 2011; 13: 670-680.

10. Mancia G, de Backer G, Dominiczak A et al. 2007 Guidelines for the management of arterial hypertension The Task Force for the Management of Arterial Hypertension of the European Society of Hypertension (ESH) and of the European Society of Cardiology (ESC). Eur Heart J, 2007; 28: 1462-1536.

11. Levey AS, Coresh J, Greene T et al. Chronic Kidney Disease Epidemiology Collaboration. Using standardized serum creatinine values in the modification of diet in renal disease study equation for estimating glomerular filtration rate. Ann Intern Med, 2006; 145: 247-254.

12. Blair JE, Zannad F, Konstam MA et al. Continental Differences in Clinical Characteristics, Management, and Outcomes in Patients Hospitalized With Worsening Heart Failure Results From the EVEREST (Efficacy of Vasopressin Antagonism in Heart Failure: Outcome Study with Tolvaptan) Program. J Am Coll Cardiol, 2008; 52: 1640-1648.

13. Gaziano TA, Bitton A, Anand A, Abrahams-Gessel S, Murphy A. Growing epidemic of coronary heart disease in low- and middle-income countries. Curr Probl Cardiol, 2010; 35: 72-115.

14. Khaw KT. Epidemiology of coronary heart disease in women. Heart, 2006; 92 (suppl. III): iii2-iii4.

15. McCartney G, Mahmood L, Leyland AH, Batty GD, Hunt K. Contribution of smoking-related and alcohol-related deaths to the gender gap in mortality: Evidence from 30 European countries. Tob Control, 2011; 20: 166-168.

16. Djoussé L, Driver JA, Gaziano JM. Relation between modifiable lifestyle factors and lifetime risk of heart failure. JAMA, 2009; 302: 394-400.

17. Bloomfield K, Grittner U, Kramer S, Gmel G. Social inequalities in alcohol consumption and alcohol-related problems in the study countries of the EU concerted action 'Gender, Culture and Alcohol Problems: a Multi-national Study’. Alcohol Suppl, 2006; 41: i26-i36.

18. Rabin BA, Boehmer TK, Brownson RC. International perspectives. Cross-national comparison of environmental and policy correlates of obesity in Europe. Eur J Public Health, 2006; 17: 53-61.

19. Bloom D, Canning D. The health and wealth of nations. Science, 2000; 287: 1207-1208.

20. Berghöfer A, Pischon T, Reinhold T, Apovian CM, Sharma AM, Willich SN. Obesity prevalence from a European perspective: A systematic review. BMC Public Health, 2008; 8: 200

21. Braunwald E. Biomarkers in heart failure. N Engl J Med, 2008; 358: 2148-2159.

22. McMurray JJV, Pfeffer MA. The year in heart failure. J Am Coll Cardiol, 2004; 44: 2398-2405.

23. Srisawasdi P, Vanavanan S, Charoenpanichkit C, Kroll MH. The effect of renal dysfunction on BNP, NT-proBNP, and their ratio. J Clin Pathol, 2010; 133: 14-23.

24. Poulain M, Doucet M, Major GC et al. The effect of obesity on chronic respiratory diseases: Pathophysiology and therapeutic strategies. CMAJ, 2006; 174: 1293-1299.

25. Rubin LJ. Primary pulmonary hypertension. N Engl J Med, 1997; 336: 111-117.

26. Guglin M. Khan H. Pulmonary hypertension in heart failure. J Card Fail, 2010; 16: 461-474.

27. Dries DL, Exner DV, Gersh BV, Domanski MJ, Waclawiw MA, Stevenson LW. Atrial fibrillation is associated with an increased risk for mortality and heart failure progression in patients with asymptomatic and symptomatic left ventricular systolic dysfunction: A retrospective analysis of the SOLVD trials. J Am Coll Cardiol, 1998; 32: 695-703.

28. Parkin DM. Global cancer statistics in the year 2000. Lancet Oncology, 2001; 2: 533-543.

29. Weidner G, Cain VS. The gender gap in heart disease: Lessons from Eastern Europe. Am J Public Health, 2003; 93: 768-770.

30. De Vogli R, Marmot M. Should socioeconomic factors be considered as traditional risk factors for cardiovascular disease, as confounders, or as risk modifiers? Dialog Cardiovasc Med, 2008; 13: 103-110. 